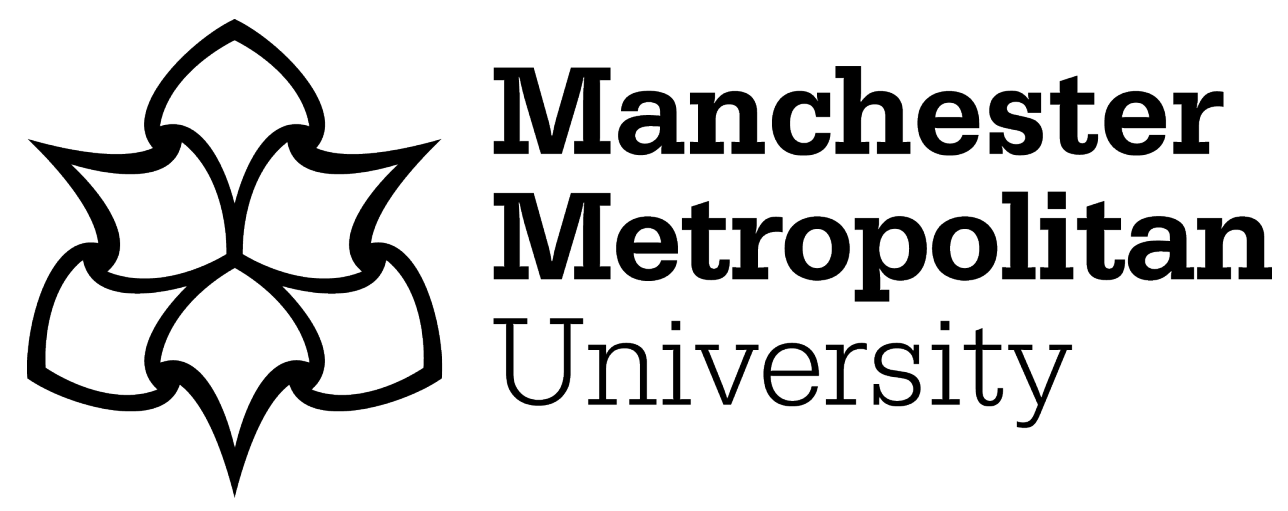

Permana, I, Ormandy, $\mathrm{P}$ and Ahmed, A ORCID logoORCID: https://orcid.org/0000-0002-6164-0656 (2019) Maintaining Harmony: How Religion and Culture are Interwoven in Managing Daily Diabetes Self-Care. Journal of Religion and Health, 58 (4). pp. 1415-1428. ISSN 0022-4197

Downloaded from: https://e-space.mmu.ac.uk/625885/

Version: Accepted Version

Publisher: Springer

DOI: https://doi.org/10.1007/s10943-019-00819-5

Please cite the published version 


\title{
Maintaining Harmony: How Religion and Culture are Interwoven in Managing Daily Diabetes Self-Care
}

\author{
Iman Permana ${ }^{1,2}$ D Paula Ormandy ${ }^{2} \cdot$ Anya Ahmed $^{2}$
}

\begin{abstract}
The lingering culture among Javanese people cannot be separated from religion, influencing how they perceive any factors that might play a role in managing any health condition. This present study aimed in exploring the perceptions and experi-ences of religion and culture in performing daily self-care among Javanese Muslim with type 2 diabetes. A qualitative study with thematic content analysis method uti-lizing in-depth semi-structured interviews was undertaken to explore the perceptions and experiences of Javanese Muslim with diabetes managing their daily self-care activity. Convenient samples of 24 participants were selected to gain a richer under-standing of self-care activity. The study identified one main theme of 'maintaining harmony' with comprised of two sub-themes: 'surrender and accept', and 'keep try-ing and leave the rest to Allah, a concept of tawakkal'. The first sub-theme consists of categories of: nerimo ing pandum, or accepting with sincerity, and tepo seliro, or being tolerance with others. The second sub-theme consists of three categories: being independent, social ties, and embracing Allah. The study also reveals the importance of Pengajian and Persadia as social resources in enhancing the capabil-ity to better self-care the condition. Thus, it also reveals the need to further develop diabetes education programmes in collaboration with religious leaders and health professionals to promote self-care to complement religious practice: Tawakkal or 'Keep trying and leave the rest to Allah'.
\end{abstract}

Keywords Self-care $\cdot$ Maintaining harmony $\cdot$ Javanese $\cdot$ Tawakkal $\cdot$ Diabetes 


\section{Introduction}

The increasing prevalence has made diabetes mellitus a global concern, especially in Indonesia. It is estimated that the number of diabetes population in Indonesia will increase from around 2.8 million in 2007 to around 5 million in 2025 (International Diabetes Federation 2007). Nevertheless, current data show that this number has exceeded two times. It has been predicted that the number has reached around 10 million in 2017 and estimated to be 16.7 million in 2045 (International Diabetes Federation 2017).

Diabetes mellitus is an illness with devastating complications, affecting $\mathrm{n}$ ot only physical, psychological, but also social aspect of a patient. Blindness, stroke, chronic kidney failure and foot ulcer leading to limb amputations are among the complications that might affect the quality of life (Krentz and Bailey 2001). Considering the effect of complications to the well-being of the patients, it is argued that a more comprehensive treatment is crucial in managing diabetes mellitus. This includes awareness on good dietary habit, keeping physically active, adhering to the medication, performing foot care, and self-monitoring blood glucose (Toobert et al. 2000; Toljamo and Hentinen 2001) as well as maintaining the psychological well-being (IDF 2012).

The involvement of religiosity in maintaining health and well-being has been welldocumented (Koenig 2012). Some studies have revealed several pathways that might play a role in that involvement such as social support (Koenig 2002; Bodenheimer and Bhuyan 2004; Newlin et al. 2008); religious belief (Koenig 2002; Parsons et al. 2006; Polzer and Miles 2007), coping strategies (Seybold and Hill 2001; Samuel-Hodge et al. 2000; Bai et al. 2009) and religious practices (Levin and Taylor 1997; McCullough et al. 2000; Coleman et al. 2006). In Indonesian context, ritual practices (Mardiyono et al. 2011), coping methods and how people regard their relationship with God (Yuniarti et al. 2013) are considered essential in managing their condition. Nevertheless, lack of adequate evidence came from Indonesia with regard to how religion and culture might play a role in managing any chronic condition such as diabetes mellitus.

To the majority of Muslims, Islam is considered as a 'way of life', which 'provides a social and legal system and governs issues such as family life, law and order, ethics, dress and cleanliness, as well as religious ritual and observance' (Hussain and El-Alami 2005. p. 1). Indeed, the influence of Islamic values and practices are clearly evident in daily activity among the Javanese. Therefore, it is essential to understand better on how Javanese Muslim with type 2 diabetes in managing their daily self-care: how they perceive and experience religion and culture in daily life. Thus, achieving this new understanding might shed some light and serve as a lesson learned on how to promote a better health care among similar culture across the globe. 


\section{Methodology}

\section{Design}

This study used a qualitative design with thematic content analysis as the method. It is argued that 'thematic analysis provides a flexible and useful research tool, which can potentially provide a rich and detailed, yet complex account of data' (Braun and Clarke 2006. p. 5). The study aimed to explore the perceptions and experiences of the Javanese Muslim with type 2 diabetes mellitus on how the perceived religion, spirituality and culture in managing their daily self-care, helping in exploring the meaning of constructs and the interrelationships between meaning (Creswell 1998).

\section{Participants of the Study}

Twenty-four participants from the Internal Medicine outpatient clinic of Rumah Sakit Pembina Kesehatan Umat Muhammadiyah (RS PKUM) or the caretaker of the health of community hospital Muhammadiyah, in Yogyakarta, Indonesia, were recruited for the interviews. The following inclusion criteria were employed: Muslim, over 18 years old, male and female, diagnosed with type 2 diabetes for over 12 months, under the care of a consultant and being treated according to the Indonesian Endocrinologist guideline or Perkeni (2011).

\section{Data Collection}

Special consideration has been taken with regard to data collection for the present study. Within Javanese culture, people prefer to have personal face-to-face communication as it is considered a more respectful way of communicating, instead of sending the inquiry by mail. A research assistant was recruited before collecting the data and trained about the research: the nature of the study, including the background and aim; who are the participants; how to gain the prospective participants; and how to approach them. Furthermore, it was intended, in the beginning, recruiting her to support the researcher in translating and explaining any language gap since she came from the same ethnical background with the participants. Nevertheless, upon data collection, the researcher could manage to establish language understanding with all participants since they could convey their messages in Bahasa Indonesia.

During data collection, the researcher and the research assistant waited in the waiting room and, based on information from the nurse in charge, would approach the prospective participants while they were waiting to be seen by the physician or for medication in the pharmacy. Verbal consent was gained before the participants completed the informed consent. A translated patient information sheet explaining the present study (with the researcher's contact details) was distributed by the researcher or the assistant within the waiting room at the outpatient clinic. Participants were given ample time to read the information sheet or if they preferred to listen to the explanation made by the researcher or the research assistant. Then, the participants were given ample time to 
consider their participation or withdrawal from the study. Participants would have the option to decide where and when they would partake the interview. Bahasa Indonesia was used when conducting the interviews and it lasted no more than $2 \mathrm{~h}$.

Debate still emerges whether to utilize saturation in qualitative studies (see Mason 2010). Moreover, several studies described that this procedure was originally referred to the grounded theory (see Creswell 2014; Bowen 2008). The researcher did not consider conducting this procedure since it was not mentioned in the thematic analysis method (see Braun and Clarke 2006) and mentioned that 24 participants have fulfilled the requirement for a sample in qualitative studies.

\section{Data Analysis}

The interview questions were qualitative in nature, exploring the experiences of managing diabetes for Muslim patients through the patient's own stories. The interview transcripts were digitally recorded and transcribed verbatim. Furthermore, the transcripts were analysed using a thematic content analytical method. Braun and Clarke (2006) explain six steps of analysing; they are: (1) familiarizing yourself with your data, (2) generating initial codes, (3) searching for themes, (4) reviewing themes, (5) defining and naming themes and (6) producing the report.

To enhance the accuracy of the account, the researcher managed to acquire the support from the supervisors to analyse the development of the themes, as a process of peer debriefing a s w ell a s p resenting n egative or discrepancy i nformation to $g$ ain a more comprehensive understanding of the phenomenon under study (Creswell 2014).

\section{Ethical Issues}

Ethical approval was obtained from the University Research Ethics Committee as well as from the internal review board of particular hospital where the study conducted. Permission was also gained from the head of the department of the diabetes clinic. The two key ethical issues needed to be considered with respect to this particular study were sample recruitment and the male researcher interviewing female participants. Islam has taught its followers to maintain respectful relationships between genders, restricting private meetings between lone males and lone females who are not legally related (muhrim). Therefore, all female participants were asked whether they preferred to be accompanied by a spouse or a relative who could act as a chaperone. Another issue regarding the confidentiality of the physicians and participants, which has already been mentioned, was solved with the utilization of name code within the excerpts.

\section{Results}

\section{Participants Characteristics}

The majority of participants were male (58.3\%), and all were Javanese and Muslim except for one participant who considered himself as Kejawen, a Javanese spiritual 
value. He considered himself as a non-practicing Muslim, but for the practicality daily administrative purposes, since all Indonesian citizens must to have an identification card which includes an option of religion, he was still considered a Muslim. The researcher decided to include this particular participant due to the intention of the study to gain an understanding of how religion and culture might influence in daily life. The age of the participants ranged between 39 to 82 years with an average of 55.5 years $(\mathrm{SD}=11.13)$. Most of the participants $(66.7 \%)$ were from a group with no or elementary level education, and the remaining were university graduates, as provided in Table 1.

\section{Maintaining Harmony}

The main theme that was generated from the interview is 'maintaining harmony'. The theme was referring to the act of surrendering and accepting the current circumstances to achieve well-being by trying to achieve balance between oneself, to the others or circumstances, and to Allah. This theme composed of two sub-themes: 'surrender and accept' and 'keep trying and leave the rest to Allah: a concept of

Table 1 Characteristics of participants by age, sex, level of education and occupation

\begin{tabular}{|c|c|c|c|c|}
\hline Participants & $\operatorname{Sex}(\mathrm{F} / \mathrm{M})$ & Age & Level of education & Occupation \\
\hline 1-A1 & $F$ & 77 & Senior high & House wife \\
\hline 8-T1 & $F$ & 58 & Elementary & House wife \\
\hline $10-\mathrm{I} 2$ & $F$ & 71 & Senior high & House wife \\
\hline $11-\mathrm{S} 5$ & $F$ & 50 & Elementary & House wife \\
\hline $13-\mathrm{S} 6$ & $F$ & 46 & No education & Business owner \\
\hline $19-\mathrm{S} 9$ & $F$ & 60 & Undergraduate & Pensioner \\
\hline $20-\mathrm{S} 10$ & $F$ & 62 & Undergraduate & Pensioner \\
\hline $30-\mathrm{K} 2$ & $M$ & 82 & Senior high & Pensioner \\
\hline $31-\mathrm{S} 14$ & $F$ & 45 & Senior high & Employee \\
\hline $35-\mathrm{S} 18$ & $M$ & 63 & Undergraduate & Pensioner \\
\hline 40-M4 & $F$ & 60 & Undergraduate & Business owner \\
\hline 44-U1 & $F$ & 57 & Junior high & House wife \\
\hline 49-S23 & $F$ & 47 & Undergraduate & Employee \\
\hline $50-\mathrm{S} 24$ & $M$ & 48 & Elementary & Labour \\
\hline $51-\mathrm{F} 1$ & $M$ & 39 & Senior high & Employee \\
\hline $54-U 2$ & $F$ & 56 & Senior high & Business owner \\
\hline $57-W 2$ & $F$ & 57 & Senior high & House wife \\
\hline $66-\mathrm{A} 5$ & $M$ & 56 & Undergraduate & Business owner \\
\hline 67-A6 & $M$ & 42 & Undergraduate & Business owner \\
\hline 77-S31 & $M$ & 64 & Elementary & Labour \\
\hline $81-\mathrm{S} 32$ & $M$ & 47 & Senior high & Employee \\
\hline 91-S34 & $M$ & 48 & Undergraduate & Civil servant \\
\hline $95-\mathrm{E} 2$ & $F$ & 39 & Senior high & Employee \\
\hline 96-M9 & $M$ & 58 & Senior high & Business owner \\
\hline
\end{tabular}


Table 2 Themes development of maintaining harmony

\begin{tabular}{|c|c|c|c|c|c|}
\hline \multirow{3}{*}{$\begin{array}{l}\text { Theme } \\
\text { Sub-themes } \\
\text { Categories }\end{array}$} & \multicolumn{5}{|c|}{ Maintaining harmony } \\
\hline & \multicolumn{2}{|c|}{ Surrendering and accepting } & \multicolumn{3}{|c|}{ Keep trying and leave the rest to Allah } \\
\hline & $\begin{array}{l}\text { Nerimo ing pan- } \\
\text { dum }\end{array}$ & Tepo seliro & Being independent & Social ties & $\begin{array}{l}\text { Embracing } \\
\text { Allah }\end{array}$ \\
\hline
\end{tabular}

tawakkal. These sub-themes represented a combination of cultural and religious perspective in supporting harmony. See Table 2.

The first sub-theme refers to the act of surrender and acceptance with oneself and to the others or circumstances to improve their well-being. Surrendering and accepting to oneself means being patient and calm, while the others or circumstances refer to how to deal with others and particular circumstances or environment.

The second sub-theme, "keep trying and leave the rest to Allah" which resembles the concept of tawakkal in Islam, comprises of three categories: being independent, social ties and embracing Allah. This sub-theme refers to the effort that participants establish to be able to self-care their circumstances, by being knowledgeable and also empowered, how managing their relationship with the society might help them in accepting their circumstances and surrender and accepting their final results of their effort to the will of Allah.

\section{Surrendering and Accepting}

The sub-theme refers to the perception of maintaining harmony by accepting current condition as a mean to cope with the circumstances. Under the discussion of this sub-theme, there were several categories that were considered essential in the effort of accepting the circumstances; those are: nerimo ing pandum and tepo seliro.

\section{Nerimo ing Pandum}

Javanese people refer the surrendering to the term of nerimo ing pandum or accepting with sincerity or ingkang nerimah or willingness (Koentjaraningrat 1985).

Maybe it (any events in life) was just coincidence (instead of destiny) (11-S5) Let say nerimo ing pandum (accepting with sincerity). So, nothing else. Accepting the way it is. If we didn't have many things to eat, just eat a little. If we had a lot, don't be too greedy (77-S31).

For participant 13-S6, her condition was regarded as 'natural law', something that happens for the sake of it. Therefore, she is just introspecting and accepting the diabetes.

As far as I know.. it's like a law.. like nature law. I was thinking what was my fault, anyway? I introspected myself. What have I done? I haven't done anything 
Accepting a condition as something usual or normal is essential in understanding what further action will be taken by the individuals. Maintaining this attitude is beneficial to lower the level of threat that the condition creates, described by the participants. Indeed, this served as the evidence of how participants preserved harmony within their own body, an opportunity of how surrendering might help towards maintaining the level of blood glucose level.

Furthermore, the participants were also addressing the notion of accepting with sincerity and by 'slowing down', an act of maintaining the psychological well-being.

Basically, according to Javanese way, everything we do we should do it slowly... don't bother to think anything, if you get tired, so be it... after you get better then you can start to work again... I followed it, and it would end up good (13-S6)

To some extent, this is in accordance with psychological care as one aspect of diabetes management program, which refers to managing any 'worries related to diabetes and self-care' (International Diabetes Federation (IDF) 2012, p. 27). However, in the absence of adequate knowledge on how to do appropriate self-care, the effort of maintaining the peace of mind has derailed the participants from their original intentions. Indeed, this notion has served as an example of the barrier of Javanese culture on self-care.

No, I haven't (known about foot care). Who will do the foot care treatment? Is it dr I? Would he do it? My feet is dirty (1-A1).

For me, it is the mind, the peace of mind. For food, let's take an example that I usually eat at $11 \mathrm{AM}$, then, I can change to 12 or $1 \mathrm{PM}$. For the afternoon, I can change it later, and it will be fine. However, the mind thinks every several minutes. Think and think all the time... well, for me, we shouldn't give much part (of the effort) to the doctor.. but we also have to do more prays (51-F1)

\section{'Teposeliro' or Being Tolerance to Others}

Another way of how Javanese people maintain harmony is to establish balance with others by adopting the spirit of 'tepo seliro' or the gesture from Javanese people in trying to place oneself in someone else's position to maintain a good relationship with others (Koentjaraningrat 1985). This study has revealed the possibility of this tenet in hindering people in achieving healthcare services that they deserve, such as in a consultation setting where a lot of patients are waiting for the consultation, or a free home care service. The feeling of awkwardness to let others waiting for her has prompted participant 10-I2 to keep her curiosity for herself.

It's because.. the time with the doctor was so tight.. I mean, "I could not have a long consultation time..I was concern of the other patients which was a lot of them waiting.. so" in case I was disturbing them.. that's all

As for participant 77-S31, he would rather take care for his own foot himself, than let the nurse did it for him in his house, since it was free, or for participant 35-S18 
who tried to respect the other by not declining the offer in any occasion, although it was contradiction to his own condition.

Yes I know (my rights to have a free service), since I had public health insurance. But to the Javanese, let say, being sensitive. We would feel uncomfortable, because it is free, why bother to ask for things (77-S31).

Well, actually, if let say I was visiting someone, I would like to give him a respect, by, if I was given something to drink, I wouldn't ask for anything else, no I wouldn't. (I would take everything) let say if only for a sip, I'd take it. At home, I would eat anything that has been served, though it wasn't delicious (35-S18)

On contradictory, participant 51-F1 or 96-M9 has different circumstances that have given him/her a better way to address their neighbour on the restriction he/she have without leaving awkward moments, since he/she understood that his/her environment already has an awareness and understanding on their condition.

I tell them that I don't eat any sweet foods, and they will say that it is alright. No one gets offended (51-F1)

I can't resist not drinking something like... the like of sweet ice tea, coffee, etc. Sometimes, when I visit my friend, they serve me with that kind of drink which I couldn't resist. But when I think I've consumed too much, I ask for a glass of water as well (96-M9).

These evidences can be served as example of how tepo seliro can play from the other side of the relationship, the healthy people. Thus, this opens an opportunity of conducting health promotional program among healthy people with embedding it with cultural aspect of tepo seliro of how to pay more respect to others with certain illnesses. Moreover, for the people of diabetes, a motivational training program might benefit them in gaining more confidence in maintaining their relationship with others in regard to managing their well-being, without fear of offending others.

\section{Keep Trying and Leave the Rest to Allah; A Concept of Tawakkal}

The second sub-theme of 'keep trying and leave the rest to Allah', a concept of Tawakkal is a religious concept that underscores the need to surrender the outcome of our effort.

\section{Being Independent}

This tenet refers to how participants in this study establish their understanding of their condition and manage to self-care themselves. The participants show their good knowledge on how to keep their regular blood check, as shown by participant 10-I2, for example. She was a retiree teacher in a senior high school and now living with her daughter, granddaughter and son-in-law. 
Usually I got checked for the fasting level first. I was a teacher at that time,, before I went to school, I stopped by at the hospital, got the blood drew then I went to the school, gave lectures, got my breakfast then went to the hospital again,, drew my blood again after $2 \mathrm{~h}$,, it was what I have done every month..

She also shows a good knowledge of how to self-care in preventing the complications, which she received from seminars held by Persadia.

It's been told in the seminar that if we feel like that we have to try to flex our feet, or by using newspapers, we crawl our toes over the newspaper, that's how we do to keep our feet moving to treat the symptoms..

\section{Embracing Allah}

Mr Makmur emphasized this tenet in his excerpt 'It's true that we make effort, but the result is the Allah's decision. So, whether the result will be good or bad, it's Allah's power'.

Furthermore, it was also emphasized by participant 30-K2 addressing the importance of accepting the circumstances as a will from God (kersane gusti Alloh).

Javanese people will say it is "kersane gusti Alloh"' (upon Allah's will) if it was being rewarded by God, everyone has to be surrender (30-K2)

Similar finding in regard of cultural influence has also been shown by Naeem (2003). This study, which was done among Kashmiri Muslim living in the UK, proposed that the belief of 'enjoying life' and 'leave the rest to Allah', has put the participants in that study to leave the outcome of their effort to Allah.

The concept of tawakkal can be found in Qur'an, which mentions the need to 'rely on', or 'turn to' Allah after performing particular activity. There are several ayat in Qur' an that support the particular tenet such as Surah 3 ayat 159 and surah 13 ayat 11 , which emphasize the essential role of surrendering to Allah after performing the action. Indeed, these ayat will act as evidence that Islam is not endorsing fatalistic behaviour. However, it is the different perspective in trying to understand Qur'an's teaching that might lead to the act of total surrendering (Grace et al. 2008). Nevertheless, the same notion is not exclusively belonged to Muslim. Studies from other religious affiliation, which mainly from Christian reveals similar notion (Pargament et al. 1998; Polzer and Miles 2007).

\section{Social Ties}

This category represents the role of society, including the family and larger environment, which include the role of 'pengajian' or religious gathering, and Persadia, an independent social organization for people with diabetes, in influencing the participants to better self-caring their circumstances.

For some respondents, coming to Pengajian or religious meeting means socializing with the others, not only listening to the ustadz or teacher. Pengajian is a 
religious activity where an ustadz or teacher was summoned to give a lecture to the society.

They mean a lot to me. Firstly, I could meet friends, we could make fun together. They can help me increasing our knowledge; I know what I didn't know before. So, if I couldn't come, I would feel pity, missing my friends (44U1)

For participant 44-U1, the religious event might play a role in relieving her need of her own circumstances, a reflection of a concept of extrinsic orientation of religion where extrinsic person uses religion as status, sociability and self-justification (Holdcroft 2006). Moreover, the close relationship among the society has proven to have a good effect on 13-S6. She felt being respected as a good person, when she found that all neighbour in the society came to see her at the hospital as well as in her house, at time of the illness. She believes that if she was not good in front of others, no one would ever bother to come to see her.

Of course, I felt that I have been paid attention by the community. It meant that I wasn't a (bad person). I am poor, and I felt I was embraced by friends, it felt good to have supports, isn't it?

Participant 44-U1 also mentioned the close relationship among the society and utilizing pengajian as a hub in talking about similar condition that they shared. For participant 95-E2, pengajian can also provide her with knowledge in daily life. Indeed, this can be served as an example of utilizing pengajian as a social hub in maintaining well-being.

Yes, we frequently talked about that (health topics)', this and that, they said 'don't let hemodialysis get us', this and that. My friends were used to chat like that (44-U1)

Sometime we invite teacher, or we just have the internal members, like the lecturer from the university, to share their knowledge. Usually, when the lecturer brings the topic on health, including how to serve the food. They said besides the cleanliness, the food we eat should also be.. I forgot. Then, about the environment, also about the cattles. They were all from the UGM. Meanwhile, the other lecturer usually discusses the problem of the recent lifestyle, teenagers, how to teach children (95-E2).

Another supporting factor from social aspect was the existence of Persatuan Diabetes Indonesia (Persadia) or Diabetes Association of Indonesian, is a nongovernmental organization aimed in establishing a place where people with diabetes along with healthcare professionals and other similar interested party can find a place together in enhancing the skill and knowledge in managing diabetes (SSDC 2013). Current study has shown the importance of Persadia in enhancing capacity and capability in maintaining daily self-care as well as providing more access to health care. Persadia is considered as a place where the members can achieve all type of social support (House in Heaney and Israel 2008). Emotional and appraisal support are provided through the interaction between members, as 
what participant 57-W2 said 'And after I join the club, I met a lot of new friends of fellow diabetic. It felt relieving some of my stress as well. After being checked, we sometimes were teasing each other how high we got but we still live normally. It is so much fun with friends'. Moreover, members are suggested to 'keep the stress down', as mentioned by participant 57-W2, which is in line with the tenet of keeping the peace of mind that several other participants mentioned in regards of how Javanese people tend to do in encountering any hardships.

Psychological support can also be gained by having time together with other members; sharing happiness. Psychological management is considered as one tenet in managing diabetes, as mentioned in the guidelines (Perkeni 2011). A study that employed a meta-analysis approach has found the association between depression and the development of complications through less physical activity, unhealthy diet and lower adherence to medication (de Groot et al. 2001; Lin et al. 2004).

Instrumental support can be achieved through the provision of blood sugar check in weekly and educational program every bi- or three-monthly basis.

Yes, from the PKU. They did it often...gave us the information...It is exclusive to Persadia club. They 54 held several activities to certain place, exercising, and lunch, after that they give you instructions, you can ask anything relating to your illness, your complaint, and medications. Doctor Irfan likes to share some thoughts (57-W2)

Moreover, peer can be served as sources of information for some participants, instead of the HCP. However, the information is not always necessarily correct. Participant 66-A5 underscores the important role of Persadia in enhancing knowledge by mentioning everyone who are not the member will get 'got stuck there'; referring to a condition of unaware of what to do due to the lack of knowledge. However, as this study further found, the existence of Persadia has not been disseminated in a wider population of people with diabetes. Several participants in this study underline the unawareness of particular program. Therefore, the suggestion to offer the engagement with Persadia by the HCP can be put as a standard procedure to every people with diabetes.

Family has been serving as a determinant factor to self-care among the participants in this study. The strong relation between parents and children, or between husband and wife and vice versa, among Javanese people has made a sense of dependency from the one who is suffering from this condition in this case, to their children or spouse. Example varied from relying to the daughter for her dietary management to support participant $1-\mathrm{A} 1$, or his wife for $30-\mathrm{K} 2$, to the feeling of taking responsibility to take care on her grandchildren in the morning, which hinders participant 8-T1 from doing walking in the morning. On the one hand, it can be served as example of how Javanese people maintain their close relationship among the member of the family, especially to the parents, since they believe that to have conflicts with the parents will hinder them from the blessings in life, which will lead to a threat in the child's life (Geertz 1995). On the other hand, it also serves as an example of how people tend to relinquish the responsibility of managing their own self-care activity to others; evidences of external locus of control. In addition, for participant 96-M9, a good family can serve as a good psychological support for him. To have a good behaviour and staying-out-of-the-trouble 
daughter means a peace of mind since he does not have anything to worry, in respect to any criminal event. Furthermore, he quotes an ayat from Qur'an in regard to the need to have a good kin, "and they who say: $\mathrm{O}$ our Lord! Grant us in our wives and our offspring the joy of our eyes, and make us guides to those who guard (against evil)" (The Qur'an, 2012).

\section{Limitations of the Study}

The limitations of the study came from the lack of the information from the other side of the topic, such as the healthcare professional, to gain a more comprehensive sound from the medical aspects, also from the Muslim cleric for the Islamic values and practices aspect. The data from HCP in regard to the current practice of self-care are needed to make a balanced opinion in trying to gain a wider and richer understanding from the other side of the research. As well as to know what the barriers and opportunities are, and the determinant factors that have played into role. Similarly, the information from Muslim cleric is also important in explaining more about how in Islamic view Muslim has to see and apprehend their own effort in maintaining well-being.

\section{Conclusion}

This study has successfully reached the aim of gaining the perception of Javanese Muslim in maintaining their self-care management in daily life. Among Javanese Muslims, maintaining harmony is important in improving their well-being. Through surrendering and accepting the circumstances, they establish the relationship with oneself, the others and Allah to achieve a better condition for them, not only physically also psychologically.

Current study has shown the interwoven dynamic between religious concept and culture among the participants. Social support from family, Pengajian and Persadia, has been playing a significant role in enhancing knowledge as well as capability in diabetes management among the participants.

It is believed that Allah has a paramount role in life among the participants, which might lead them into various way of achieving well-being, fatalistic or tawakkal, a concept of keep trying and leave the outcome to Allah. There are several determinant factors that might play into role such as socio-economical status, self-agency as well as structural aspect. Thus, it is believed that those aspects might act as barrier to self-care, on the one hand. On the other hand, they also open opportunities to a better self-care management, not only in personal scope, but also in a wider society, with the involvement of the political will from the authority. Therefore, the need to establish a collaborative role of a Muslim clerk into diabetes self-care education program might serve as an option to develop a more comprehensive way of delivering the educational program. 


\section{References}

Bai, Y.-L., Chiou, C.-P., \& Chang, Y.-Y. (2009). Self-care behaviour and related factors in older people with Type 2 diabetes. Journal of Clinical Nursing, 18(23), 3308-3315.

Bodenheimer, T., \& Bhuyan, K. K. (2004). Health promotion through self-care and community participation: Elements of a proposed programme in the developing countries. BMC Public Health, 4(11), 12.

Bowen, A. B. (2008). Naturalistic inquiry and the saturation concept: A research note. Qualitative Research, 8(1), 137-152.

Braun, V., \& Clarke, V. (2006). Using thematic analysis in psychology. Qualitative Research in Psychology, 3(2), 77-101. https://doi.org/10.1191/1478088706qp063oa.

Coleman, C. L., Holzemer, W. L., Eller, L. S., Corless, I., Reynolds, N., Nokes, K. M., et al. (2006). Gender differences in use of prayer as a self-care strategy for managing symptoms in African Americans living with HIV/AIDS. Journal of the Association of Nurses in AIDS Care, 17(4), 16-23.

Creswell, J. W. (1998). Qualitative inquiry and research design: Choosing among five traditions. Thousand Oaks: Sage Publishing.

Creswell, J. W. (2014). Research design. Qualitative, quantitative, and mixed methods approaches (4th ed.). London: Sage.

de Groot, M., Anderson, R., Freedland, K. E., Clouse, R. E., \& Lustman, P. J. (2001). Association of depression and diabetes complication, a meta analysis. Psychosomatic Medicine, 63(4), 619-630.

Geertz, C. (1995). The Javanese family. United Nations University Press, Tokyo. http://archive.unu.edu/ unupress/unupbooks/uu13se/uu13se09.htm.

Grace, C., Begum, R., Subhani, S., Kopelman, P., \& Greenhalgh, T. (2008). Prevention of type 2 diabetes in British Bangladeshis: Qualitative study of community, religious, and professional perspectives. BMJ. https://doi.org/10.1136/bmj.a1931.

Heaney, C. A., \& Israel, B. A. (2008). Social Networks and Social Support. In K. Glanz, B. K. Rimer, \& K. Viswanath (Eds.), Health behavior and health education (4th ed.). San Fransisco: Wiley.

Holdcroft, B. (2006). What is religiosity? Catholic Education: A Journal of Inquiry and Practice, 10(1), 15.

Hussain, A., \& El-Alami, K. (2005). Faith guides for higher education. A guide to Islam. Leeds: The Subject Centre for Philosophical and Religious Studies.

International Diabetes Federation (IDF). (2007). IDF Diabetes Atlas-2007 (3rd ed.).

International Diabetes Federation (IDF). (2012). IDF-guideline-for-type-2-diabetes. Belgium: IDF.

International Diabetes Federation (IDF). (2017). IDF Diabetes Atlas-2017 (8th ed.).

Koenig, H. G. (2002). The connection between psychoneuroimmunology and religion. In H. G. Koenig \& H. J. Cohen (Eds.), The link between religion and health. Psychoneuroimmunology and the faith factor. New York: Oxford University Press, Inc.

Koenig, H. G. (2012). Religion, spirituality, and health: The research and clinical implications. ISRN Psychiatry, 2012, 1-33.

Koentjaraningrat. (1985). Javanese culture. Singapore: Oxford University Press.

Krentz, A. J., \& Bailey, C. J. (2001). Type 2 diabetes in practice. London: Royal Society of Medicine Ltd.

Levin, J. S., \& Taylor, R. J. (1997). Age differences in patterns and correlates of the frequency of prayer. The Gerontologist, 37(1), 75-88.

Lin, E. H. B., Katon, W., Von Korff, M., Rutter, C., Simon, G. E., Oliver, M., et al. (2004). Relationship of depression and diabetes self-care, medication adherence, and preventive care. Diabetes Care, 27(9), 2154-2160. https://doi.org/10.2337/diacare.27.9.2154.

Mardiyono, M., Songwathana, P., \& Petpichetchian, W. (2011). Spirituality intervention and outcomes, corner stone of holistic nursing practice. Nurse Media Journal of Nursing, 1(1), 11.

Mason, M. (2010). Sample size and saturation in $\mathrm{PhD}$ studies using qualitative interviews [63 paragraphs]. Forum Qualitative Sizialforschung/Forum: Qualitative Social Research, 11(3). http://nbnresolving.de/urn:nb:de:0114-fqs100387.

Naeem, A. G. (2003). The role of culture and religion in the management of diabetes: A study of Kashmiri men in Leeds. Perspectives in Public Health, 123(2), 6.

Newlin, K., Melkus, G. D., Tappen, R., Chyun, D., \& Koenig, H. G. (2008). Relationships of religion and spirituality to glycemic control in Black women with type 2 diabetes. Nursing Research, 57(5), 331-339. https://doi.org/10.1097/01.NNR.0000313497.10154.66. 
Pargament, K. I., Kennell, J., Hathaway, W., Grevengoed, N., Newman, J., \& Jones, W. (1998). Religion and the problem-solving process: Three styles of coping. Journal for the Scientific Study of Religion, 27(1), 90-104.

Parsons, S. K., Cruise, P. L., Davenport, W. M., \& Jones, V. (2006). Religious beliefs, practices and treatment adherence among individuals with HIV. AIDS Patient Care STDS, 20(2), 16.

Perkeni. (2011). Konsensus Pengelolaan dan Pencegahan Diabetes Melitus tipe 2 di Indonesia 2011 (the 201153 Indonesian Consensus on the Management on type II Diabetes Mellitus).

Polzer, R. L., \& Miles, M. S. (2007). Spirituality in African Americans with diabetes: Self-management through a relationship with God. Qualitative Health Research, 17(2), 176-188. https://doi. org/10.1177/1049732306297750.

Samuel-Hodge, C. D., Headen, S. W., Skelly, A. H., Ingram, A. F., Keyserling, T. C., Jackson, E. J., et al. (2000). Influences on day-to-day self-management of type 2 diabetes among African-American women: Spirituality, the multi-caregiver role, and other social context factors. Diabetes Care, 23(7), 928-933.

Seybold, K. S., \& Hill, P. C. (2001). The role of religion and spirituality in mental and physical health. Current Directions in Psychological Science (Wiley-Blackwell), 10(1), 21-24.

SSDC. (2013). Diabetes champion (Pandu diabetes). SS Diabetes Care. Retrieved from 10 June, 2013. http://ssdiacare.com/?prm=profil\&id=35.

Toljamo, M., \& Hentinen, M. (2001). Adherence to self-care and glycaemic control among people with insulin-dependent diabetes mellitus. Journal of Advanced Nursing, 34(6), 780-786. https://doi.org/1 0.1046/j.1365-2648.2001.01808.x.

Toobert, D. J., Hampson, S. E., \& Glasgow, R. E. (2000). The summary of diabetes self-care activities measure: Results from 7 studies and a revised scale. Diabetes Care, 23(7), 943-950. https://doi. org/10.2337/diacare.23.7.943.

Yuniarti, K. W., Dewi, C., Ningrum, R. P., Widiastuti, M., \& Asril, N. M. (2013). Illness perception, stress, religiosity, depression, social support, and self management of diabetes in Indonesia. Yogyakarta, Indonesia: Universitas Gadjah Mada. 